\title{
Ashy dermatosis: A comprehensive review
}

\section{Bibush Amatya}

\author{
Resident Dermatology, Institute of Medicine, Tribhuvan University Teaching Hospital, Kathmandu, Nepal
}

Corresponding author: Dr. Bibush Amatya, E-mail: doc_bibush@hotmail.com

\begin{abstract}
Introduction: The confusing macular hyperpigmentary disorders of uncertain aetiology include ashy dermatosis, erythema dyschromicum perstans (EDP) and lichen planus pigmentosus (LPP). They are characterized by insidious development of bluish grey macules involving the face, neck and upper trunk. The usual course of the conditions is progressive and persistent differentiating them from idiopathic eruptive macular pigmentation, which resolves in months. Materials and Methods: A comprehensive literature search was conducted in PUBMED, PUBMED CENTRAL, SCOPUS, MEDLINE, and GOOGLE SCHOLAR databases using the keywords ashy dermatosis, erythema dyschromicum perstans, lichen planus pigmentosus, acquired hyperpigmentation and facial melanosis. All the articles published irrespective of the date of publication were accessed. Results: The prevalence of ashy dermatosis is higher in Asia, Central and South America. The exact cause of ashy dermatosis is unknown but associations with contrast agents, infections and infestations have been reported. Presence of an erythematous border at the initial stage differentiates erythema dyschromicum perstans from ashy dermatosis, which lacks the initial erythematous phase. Lichen planus pigmentosus, on the other hand, may have lesions of lichen planus in other body sites with hyperpigmentation of the basal layers with or without vacuolar degeneration. The topical agents used for the treatment of these conditions have included cosmetics and camouflage, topical calcineurin inhibitors and narrow band ultraviolet therapy while the systemic agents include vitamin A capsules, clofazimine and dapsone. Conclusion: The proper diagnosis of these conditions can be aided by the use of an algorithm. A host of topical and systemic agents with variable efficacy have been used in the treatment of these conditions. No randomized controlled trials have been done till date assessing the efficacy of these agents. The isolated case reports that have assessed the use of narrow band ultraviolet therapy and topical tacrolimus ointment have shown promising results. Larger scale controlled trials are recommended to truly assess the efficacy and safety of these agents in the treatment of these hyperpigmentary disorders.
\end{abstract}

Key words: Ashy dermatosis; EDP; LPP

\section{INTRODUCTION}

Ashy dermatosis, first described by Ramirez in 1957 [1], is an idiopathic acquired macular hyperpigmentation disorder. The descriptive term "ashy or los cenicientos" was used because of the ashy blue-grey color of the lesions. The sites commonly affected include face, neck, trunk and upper limbs but any region of the body can be affected [2]. Convit, Kerdel-Vegas and Rodriguez in their case series reported the presence of raised erythematous borders in the early stages and proposed the term "erythema dyschromicum perstans (EDP)" [3]. Other authors however have noted that EDP can occur without marginal erythema [4,5]. Bhutani and his colleagues described similar hyperpigmented macules over the flexures and photoexposed areas in 40 Indian patients, about a third of whom had associated features of lichen planus on clinical evaluation and histopathological examination [6]. These entities were subsequently labeled as "lichen planus pigmentosus (LPP)".

\section{MATERIALS AND METHODS}

A comprehensive literature search was conducted in PUBMED, PUBMED CENTRAL, SCOPUS, MEDLINE, and GOOGLE SCHOLAR databases using 
the keywords ashy dermatosis, erythema dyschromicum perstans, lichen planus pigmentosus, acquired hyperpigmentation and facial melanosis. All the articles published irrespective of the date of publication were accessed. The photographs displayed were taken by the author from the patients visiting the outpatient department of the Department of Dermatology at the Institute of Medicine, Tribhuvan University Teaching Hospital, Kathmandu, Nepal.

\section{Ethics Statement}

The photographs displayed in this review article were taken and illustrated after obtaining verbal consent from the patients. Attempts have been made to ensure that the photographs do not reveal the identity of the participants.

\section{RESULTS}

\section{Epidemiology}

The exact incidence and prevalence of these acquired macular hyperpigmentary disorders is unknown. Onset can occur at any age but the mean age of occurrence is usually in the $2^{\text {nd }}$ decade of life $[7,8]$. The condition is most common in Asia and Central and South America, as the majority of the published cases have been from those regions [7-9]. Silverberg and colleagues reported that most of the prepubertal patients suffering from Ashy dermatosis were Caucasians (52\%) and Hispanics (36\%) [10]. There have been two case reports of Indian children with this condition $[11,12]$. The condition affects both the sexes but is more common in women [7-9].

\section{Aetiology and Associations}

The exact cause of ashy dermatosis is unknown. However, it has been reported in association with the ingestion of ammonium nitrate and barium sulfate. The reported associated infections and infestations include hepatitis $\mathrm{C}$ virus infection, HIV infection and whipworm infestation [7-9].

\section{Pathophysiology}

The pathophysiology of ashy dermatosis or erythema dyschromicum perstans is currently unknown. An association with contrast agents, viral infections and worm infestations have been reported [7-9]. It has been hypothesized that an immunological response to these agents may lead to the hyperpigmentation [13]. Furthermore, Numata and his colleagues have hypothesized that a weaker immune response leads to ashy dermatosis while a stronger response can cause erythema dyschromicum perstans [13].

\section{Genetics}

Only one study has showed that the presence of HLADR4 *0407 is a risk factor in Mexican mestizos [14].

\section{Pathology}

There are no pathognomonic findings in the histology of the lesions [2]. The most common finding in the epidermis is vacuolar degeneration of basal cells leading to pigmentary incontinence and accumulation of melanophages in the papillary dermis [9]. The dermal changes include oedema of the papillary dermis and an infiltrate of lymphocytes and histiocytes [15]. VasquezOchoa et al. in their study, demonstrated predominance of CD8 + T lymphocytes and ICAM-1 + keratinocytes in the infiltrate [16]. An interesting point to note is the absence of vacuolization of basal cells and decreased infiltrate in inactive lesions [17].

On direct immunofluorescence, there is colloid staining of IgM and $\mathrm{C} 4$ along with deposition of fibrinogen at the dermoepidermal junction [18].

\section{Clinical Features}

The condition usually starts in young adults between the first and second decades of life [12]. The initial presentation is that of slowly increasing asymptomatic macules measuring $0.5 \mathrm{~cm}-2 \mathrm{~cm}$ with varying shades of gray [12]. They typically start in the trunk (Fig. 1) and then spread to involve the face and extremities (Fig. 2a and b) [12]. However, most of the cases seen in our hospital have predominant involvement of the face, neck (Fig. 3a) and upper trunk with absence of involvement of the extremities. The lesions also tend to follow a photodistribution with relative sparing of the neck creases (Fig. $3 \mathrm{~b}$ and c). Some authors $[7,12]$ have described presence of an elevated erythematous palpable border measuring 1-2 mm in width surrounding the lesions in the early phase. Most authors $[12,19]$ agree that border eventually disappears with a few months. The initial erythematous border may not be present in all the cases and are especially difficult to appreciate in patients with Fitzpatrick skin types IV, V [12]. There is sparing of palms, soles, scalp, nails, and mucous membranes. 


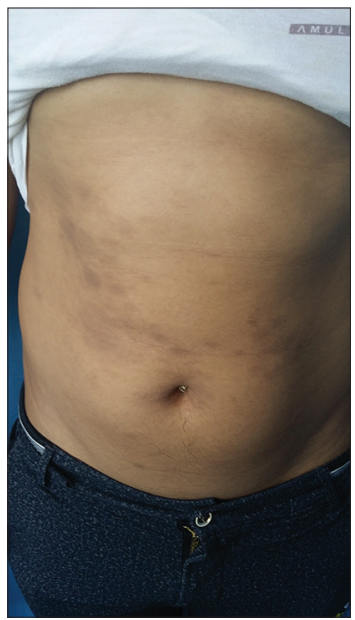

Figure 1: Multiple gray macules on the trunk.

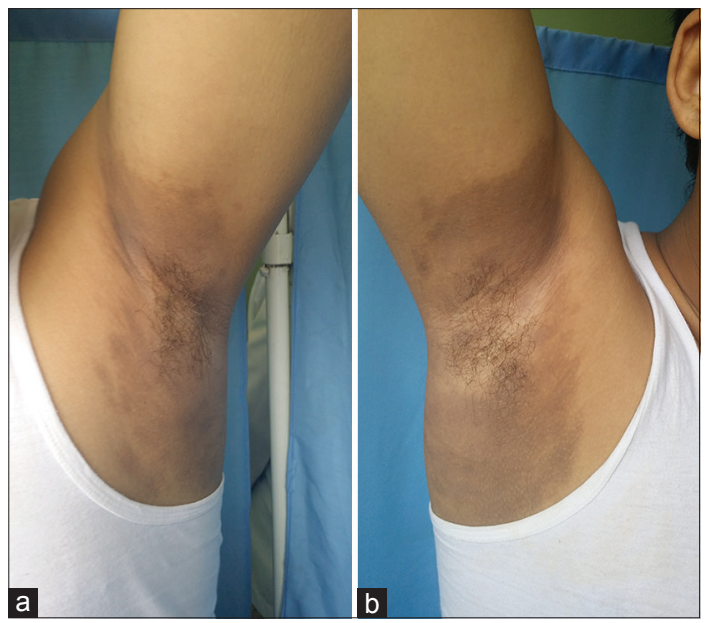

Figure 2: (a) Gray macules of ashy dermatosis on left axilla. (b) Similar lesions on the right axilla of same patient.

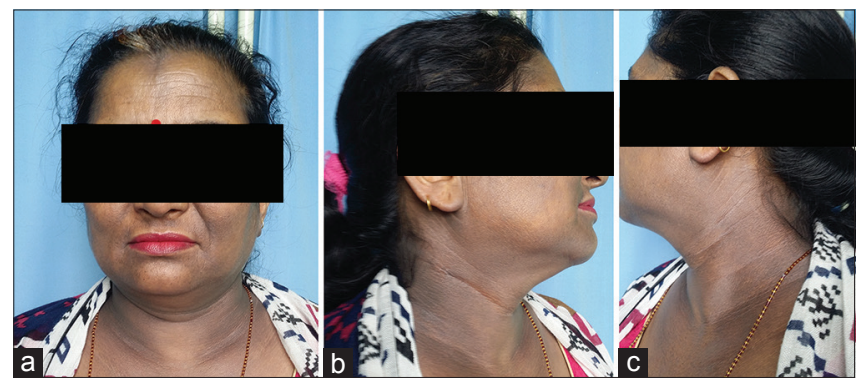

Figure 3: (a) Involvement of the cheeks and neck. (b) Sparing of neck folds. (c) Involvement of neck, and upper trunk while sparing the folds.

\section{Differential Diagnoses}

The main conditions simulating ashy dermatosis and erythema dyschromicum perstans are lichen planus pigmentosus, idiopathic eruptive macular pigmentation and Riehl's melanosis.

The other differentials are the pigmented macules of the late pinta, post-inflammatory hyperpigmentation, multiple fixed drug eruption, haemochromatosis, Addison's disease, melasma, leprosy and confluent and reticulated papillomatosis of Gougerot and Carteaud [2] .

\section{Erythema dyschromicum perstans and ashy dermatosis}

The only significant difference between erythema dyschromicum perstans and ashy dermatosis has been the presence of a palpable erythematous border measuring $1-2 \mathrm{~mm}$ in width in the early stages of the former [12,19]. However, the border can be difficult to discern in darker skinned populations [12]. A descriptive term such as macular pigmentation of uncertain aetiology should be used to describe the two conditions, which have similar clinical picture, histology and prognosis [20].

\section{Lichen planus pigmentosus}

The differential generating the most controversy is lichen planus pigmentosus. In this condition, there are hyperpigmented brown macules over the exposed areas [2], which can be associated with pruritus [21,22] and with frequent remissions and exacerbations. Both ashy dermatosis and lichen planus pigmentosus are characterized by presence of pigment laden macrophages in the papillary dermis and vacuolar degeneration of the basal cells in the epidermis. MaxJoseph spaces, resulting from liquefactive degeneration of the basal layer with separation from underlying lamina propria, can observed in cases of lichen planus pigmentosus but are absent in ashy dermatosis. A band-like infiltrate present in lichen planus is absent in erythema dyschromicum perstans. However, the subpopulations of lymphocytes and keratinocytes are similar in both the conditions [2]. As a result, some authors still dispute whether the conditions are clinically and histopathologically distinct from one another [16,23].

\section{Idiopathic eruptive macular pigmentation}

Idiopathic eruptive macular pigmentation as the name suggests is a rare condition characterized by eruption of brownish, non-confluent, asymptomatic macules involving the trunk, neck and proximal extremities in children and adolescents [24]. The two main differences between this condition and ashy dermatosis are frequent resolution and basal layer hyperpigmentation without degeneration in the latter.

\section{Riehl's melanosis}

Riehl's melanosis, a pigmented contact dermatitis to cosmetics or textiles $[25,26]$ is characterized by 
reticular pigmentation, often with satellite perifollicular pigmented macules. It occurs at the site of contact, can be preceded by erythema and pruritus and patients usually demonstrate positivity to allergic patch tests [27].

\section{Approach to diagnosis}

An algorithm devised by Chandran and Kumarasinghe [20] can be used to make an approach to diagnosis in these conditions. The salient features are:

Lichen planus pigmentosus: Past or current evidence of lichen planus, with supportive histological features including band-like infiltrates, basal layer hyperpigmentation and presence or absence of vacuolar degeneration of basal cells [20].

Ashy dermatosis: Large macules $(>5 \mathrm{~cm}$ ) or combination of small $(<5 \mathrm{~cm})$ and large macules with grayish tinge and absence of erythematous border.

Erythema dyschromicum perstans: Large macules $(>5 \mathrm{~cm})$ or combination of small $(<5 \mathrm{~cm})$ and large macules with grayish tinge and presence of erythematous border.

Idiopathic eruptive macular pigmentation: Small $(<5 \mathrm{~cm})$ brown macules resolving in few months.

Riehl's melanosis: Persistent small brown macules $(<5 \mathrm{~cm})$ that may be accompanied by erythema and pruritus and are usually caused by cosmetics and clothing.

\section{Prognosis}

Although the initial erythematous phase in erythematous dyschromicum perstans tend to subside after several months, the residual hyperpigmentation persists and may gradually increase in size [3].

\section{Treatment Options}

Randomized controlled trials for the treatment of ashy dermatosis have not been performed till date [28]. There are no consistently effective treatment options for these conditions.

\section{Topical agents}

\section{Cosmetics and camouflage creams}

These creams while not bringing any change to the lesions appear to improve the appearance of the lesions by decreasing the contrast with the surrounding uninvolved skin.

\section{Narrow band ultraviolet therapy}

Tlougan and colleagues [28] advocate the use of narrow band ultraviolet therapy. However, the recommendation is based on a single case without any mention of the dose, duration of the treatment and degree of improvement using an outcome measure.

\section{Tacrolimus ointment}

Mahajan and colleagues [29] report that in two patients with erythema dyschromicum perstans, topical tacrolimus $0.1 \%$ ointment applied twice daily to the affected areas resulted in significant improvement after 3 weeks. Controlled trials are recommended to ascertain whether the benefit is statistically significant.

\section{Fractionated laser}

Non-ablative $1550 \mathrm{~nm}$ fractional laser therapy was not considered to be effective for the treatment of erythema dyschromicum perstans [30]. Moreover, the therapy resulted in postinflammatory hyperpigmentation secondary to laser burns.

\section{Systemic agents Clofazimine}

Two studies were conducted in the last 20 years, assessing the efficacy of clofazimine for erythema dyschromicum perstans. The patients were given tablet clofazimine $100 \mathrm{mg}$ daily for 3 months $[31,32]$. The response rates varied from $66 \%$ to $87 \%$. The side effects noted were discolourations of the skin, cornea and body fluids along with gastrointestinal intolerance. One of the reasons for not using clofazimine more often could be the drug resulting in greater dyspigmentation compared to the original condition.

\section{Dapsone}

Dapsone, another antibiotic and anti-inflammatory agent, was used by Kontochristopoulos et al. in 1998 [33]. They have reported that two patients with erythema dyschromicum perstans responded remarkably well to oral dapsone therapy at $100 \mathrm{mg}$ per day for three months. Subsequently, Bahadir et al. used oral dapsone therapy in one case of erythema dyschromicum perstans with excellent results [21]. However, dapsone is associated with haemolysis and fatal dapsone hypersensitivity syndrome and should be used only with caution in controlled settings.

\section{Vitamin A}

Bhutani gave Vitamin A capsules to 140 patients with lichen planus pigmentosus at dosages of 100,000 units 
per day for 15 days followed by rest for 15 days. Due to the large number of patients lost to follow up, it is difficult to ascertain the exact benefit of this agent in the treatment of lichen planus pigmentosus. The authors do mention that nine out of 12 patients showed good to excellent response after 10 or more courses of the drug [34].

\section{DISCUSSION}

Acquired macular hyperpigmentary disorders have confused and confounded dermatologists for many years. The lack of a clear aetiology and pathophysiology has only added to the confusion.

However, clinical and histopathological evaluation has provided a base from which the macular hyperpigmentary disorders can then be differentiated. Presence of bluish-gray macules with the presence of an erythematous border in the initial stages can be labeled as erythema dyschromicum perstans while its absence signifies ashy dermatosis. Similarly, the presence of lichen planus lesions in other body sites, past history of lichen planus, presence of basal cell layer pigmentation with or without vacuolization, leads to a diagnosis of lichen planus pigmentosus $[35,36]$.

Riehl's melanosis is characterized by presence of persistent brown small macules less than $5 \mathrm{~cm}$ in size in the areas previously in contact with cosmetics or clothes. When there is presence of similar lesions that usually resolve on their own, the clinician can confidently albeit retrospectively, label the diagnosis as idiopathic eruptive macular pigmentation.

The treatment options for the conditions are rather limited and more often than not frustrating for the patients as well as dermatologists. While clofazimine and dapsone have been tried in the past, they are only useful in the initial inflammatory phase and carry a burden of unwanted side effects that can be more distressing than the original symptoms.

The three options showing promising results are narrow band ultraviolet therapy, topical tacrolimus ointment and oral vitamin A capsules. There is paucity of studies advocating the use of these agents but there is plenty of room for large scale studies to be conducted to determine the efficacy and safety of these agents in the treatment of ashy dermatosis and lichen planus pigmentosus.

\section{CONCLUSION}

An approach to diagnosis for the acquired macular pigmentary disorders of unknown significance can be made using the algorithm devised by Chandran and Kumarasinghe [20]. This allows the clinician to make a confident diagnosis by excluding the other two simulatory conditions, idiopathic eruptive macular pigmentation and Riehl's melanosis. The promising therapeutic agents based on the isolated case reports include narrow band ultraviolet therapy and topical application of $0.1 \%$ tacrolimus ointment. The author recommends large blinded controlled trials to truly assess the efficacy and safety of these agents in the treatment of these conditions.

\section{REFERENCES}

1. Ramírez CO. Los cenicientos: Problema Clinica. Memoria del Primer Congresso Centroamericano de Dermatologica, San Salvador. 1957:122-30.

2. Cutri FT, Ruocco E, Pettinato G, Ciancia G. Lichen planus pigmentosus-like ashy dermatosis. Dermatol Reports. 2011;3:e46.

3. Convit J, Kerdel-Vegas F, Rodríguez G. Erythema dyschromicum perstans: a hitherto undescribed skin disease. J Invest Dermatol. 1961;36:457-62.

4. Chang SE, Kim HW, Shin JM, Lee JH, Na JI, Roh MR, et al. Clinical and histological aspect of erythema dyschromicum perstans in Korea: a review of 68 cases. J Dermatol. 2015;42:1053-7.

5. Muñoz C, Chang AL. A case of Cinderella: erythema dyschromicum perstans (ashy dermatosis or dermatosis cinecienta). Skinmed. 2011;9:63-4.

6. Bhutani LK, Pandhi RK, Bedi TR. Lichen planus pigmentosus. Dermatologica. 1974;149:43-50.

7. Torrelo A, Zaballos P, Colmenero I, Mediero IG, de Prada I, Zambrano A. Erythema dyschromicum perstans in children: a report of 14 cases. J Eur Acad Dermatol Venereol. 2005;19:422-6.

8. Schwartz RA. Erythema dyschromicum perstans: the continuing enigma of Cinderella or ashy dermatosis. Int J Dermatol. 2004;43:230-2.

9. Osswald SS, Proffer LH, Sartori CR. Erythema dyschromicum perstans: a case report and review. Cutis. 2001;68:25-8.

10. Silverberg NB, Herz J, Wagner A, Paller AS. Erythema dyschromicum perstans in prepubertal children. Pediat Dermatol. 2003;20:398-403.

11. Ummap PS. Erythema dyschromicum perstans. Indian J Dermatol. 1996;41:68-9.

12. Keisham C, Sarkar R, Garg VK, Chugh S. Ashy dermatosis in an 8-year-old Indian child. Indian Dermatol Online J. 2013;4:30-2.

13. Numata T, Harada K, Tsuboi R, Mitsuhashi Y. Erythema Dyschromicum Perstans: Identical to Ashy Dermatosis or Not? Case Rep Dermatol. 2015;7:146-50.

14. Correa MC, Memije EV, Vargas-Alarcón G, Guzmán RA, Rosetti F, Acuña-Alonzo V, Martinez-Rodriguez N. Granados J. HLADR association with the genetic susceptibility to develop ashy dermatosis in Mexican Mestizo patients. J Am Acad Dermatol. 2007;56:17-20.

15. Imanishi H, Tsuruta D, Kobayashi $H$, Ishii M, Nakagawa K. Two Cases of Unilateral Ashy Dermatosis. Case Rep Dermatol. 2011;3:1-4.

16. Vasquez-Ochoa LA, Isaza-Guzman DM, Orozco-Mora B, RestrepoMolina R, Trujillo-Perez J, Tapia FJ. Immunopathologic study of 


\section{www.odermatol.com}

erythema dyschromicum perstans (ashy dermatosis). Int J Dermatol. 2006;45:937-41.

17. Lapeere H, Boone B, Schepper SD, Verhaeghe E, Ongenae K, Geel NV, et al. Erythema dyschromicum perstans. In: Wolff K, Goldsmith L, Katz SI, Gilchrest BA, Paller AS, Leffell DJ, editors. Fitzpatrick's Dermatology in General Medicine. vol 1. New York: McGraw-Hill; 2008:640.

18. Tschen JA, Tschen EA, McGavran MH. Erythema dyschromicum perstans. J Am Acad Dermatol. 1980;2:295-302.

19. Ghosh A, Coondoo A. Lichen Planus Pigmentosus: The Controversial Consensus. Indian J Dermatol. 2016;61:482-6.

20. Chandran V, Kumarasinghe SP. Macular pigmentation of uncertain aetiology revisited: two case reports and a proposed algorithm for clinical classification. Australas J Dermatol. doi:10.1111/ajd.12428

21. Bahadir S, Cobanoglu U, Cimsit G, Yayli S, Alpay K. Erythema Dyschromicum Perstans: Response to Dapsone therapy: Int J Dermatol. 2004;43:220-2.

22. Volz A, Metze D, Böhm M, Brucker-Tuderman L, Nashan D. Idiopathic eruptive macular pigmentation in a 7-year-old girl: case report and discussion of differences from erythema dyschromicum perstans. Br J Dermatol. 2007;157:839-40.

23. Naidorf KF, Cohen SR. Erythema dyschromicum perstans and lichen planus. Arch Dermatol. 1982;118:683-5.

24. Sanz de Galdeano C, Léauté-Labrèze C, Bioulac-Sage P, Nikolic M, Taïb A. Idiopathic eruptive macular pigmentation: report of five patients. Pediatr Dermatol. 1996;13:274-7.

25. Pires MC, Manoel Silva dos Reis V, Mitelmann R, Moreira F. Pigmented contact dermatitis due to Plathymenia foliosa dust. Contact Dermatitis. 1999;40:339.

26. Nath AK, Thappa DM. Kumkum-induced dermatitis: An analysis of 46 cases. Clin Exp Dermatol. 2007;32:385-7.

27. Tritsch H, Greither A. Erythrosis pigmentata faciei. Arch Derm Syphilol. 1955;199:221-7.

28. Tlougan BE, Gonzalez ME, Mandal RV, Kundu RV, Skopicki DL. Erythema dyschromicum perstans. Dermatol Online J. 2010:16:17.

29. Mahajan VK, Chauhan PS, Mehta KS, Sharma AL. Erythema
Dyschromicum Perstans: Response to Topical Tacrolimus. Indian J Dermatol. 2015;60:525.

30. Kroon MW, Wind BS, Meesters AA, Wolkerstorfer A, van der Veen JPW, Bos JD, et al. Non-ablative $1550 \mathrm{~nm}$ fractional laser therapy not effective for erythema dyschromicum perstans and postinflammatory hyperpigmentation: a pilot study. J Dermatolog Treat. 2012;23:339-344.

31. Piquero-Martin J, Pearez-Alfonzo R, Abrusci V, Briceno L, Gross A, Mosca W, Tapia F, Convit J. Clinical trial with clofazimine for treating erythema dyschromicum perstans: evaluation of cellmediated immunity. Int J Dermatol. 1989;28:198.

32. Baranda L, Torres-Alavarez B, Cortes-Franco R, Moncada B, Portales-Perez DP, Gonzalez-Amaro R. Involvement of cell adhesion and activation molecules in the pathogenesis of erythema dyschromicum perstans (ashy dermatitis): the effect of clofazimine therapy. Arch Dermatol. 1997;133:325.

33. Kontochristopoulos G, Stavropoulos P, Panteleos D, Aroni K. Erythema dyschromicum perstans: response to dapsone therapy. Int J Dermatol. 1998;37:796.

34. Bhutani LK, George M, Bhate SM. Vitamin A in the treatment of lichen planus pigmentosus. British J Dermatol. 1979;100:473-5.

35. Nag F, Ghosh A, Chatterjee G, Choudhary N. Lichen planus pigmentosus: two atypical presentation. Our Dermatol Online. 2013;4:78-9.

36. Kilinc F, Akbas A, Sener S, Yavuz SO, Akkus A, Aktas A. A case of facial lentiginous lichen planus pigmentosus associated with Hashimoto's thyroiditis and diabetes mellitus. Our Dermatol Online. 2015;6:440-2.

Copyright by Bibush Amatya. This is an open-access article distributed under the terms of the Creative Commons Attribution License, which permits unrestricted use, distribution, and reproduction in any medium, provided the original author and source are credited.

Source of Support: Nil, Conflict of Interest: None declared. 